\title{
Age, aging and labor-consequences for individuals and institutions
}

\author{
Michael Falkenstein • Joachim Möller • \\ Ursula M. Staudinger
}

Published online: 11 October 2011

(C) Institut für Arbeitsmarkt- und Berufsforschung 2011

Many advanced Western countries have been and will be facing both aging and shrinking populations in the decades to come. The challenges resulting from this demographic change for the labor market, the educational system and the welfare state are serious. However, they do not have to lead into a deep and inevitable crisis if political decision-makers, firms, society and individuals alike are willing to undertake the necessary changes. It is essential to start the necessary transformations now! In particular, institutions, working conditions and individual behavior need to be adjusted in order to keep elderly workers longer fit and healthy and to improve work/life balance over the life course. As a consequence, this empowers people to stay in employment longer than previously. This includes that traditional strategies of excluding older persons from further working and training are abandoned. In general, the one-sided negative view of the aging process has to be reconsidered.

These were the guiding principles of the workshop "Age, aging and labor-consequences for individuals and institutions" that took place in April 2010 in Nuremberg and that was commonly hosted by the Institute for Employment Research (IAB) and the Jacobs Center on Lifelong Learning and Institutional Development of the Jacobs University Bre-

M. Falkenstein ( $\varangle)$

Leibniz Research Centre for Working Environment and Human Factors, Dortmund, Deutschland

e-mail: Falkenstein@ifado.de

J. Möller

Institute for Employment Research, Nürnberg, Deutschland

e-mail: joachim.moeller@iab.de

U.M. Staudinger

Jacobs University Bremen, Bremen, Deutschland

e-mail: u.staudinger@jacobs-university.de men. In addition, the workshop should lay the foundation for an interdisciplinary research network.

The articles published in this volume of the journal are a sample of the papers presented at that workshop and cover different aspects of the overall topic. They represent a broad disciplinary spectrum reaching from economics and business administration up to psychology and neuroscience. The multidisciplinary approach opens up the opportunity to take a systemic look on aging and to analyze its consequences at different levels-from the individual via the establishment level up to the society and the national economy as a whole.

Staudinger and Bowen ("A Systematic Approach to Aging in the Work-Context") discuss the key principles that guide the research about the relationship between work and aging conducted at Jacobs Center on Lifelong Learning and Institutional Development (JCLL). They argue that a systemic, interdisciplinary and process-oriented approach is needed to understand the complex, dynamic and contextsensitive interaction between aging and work. The recognition that aging is an ongoing, life-long process that does not start at a particular age can help to identify the contextual conditions that facilitate or hinder the exploitation of the potential for productive development across the life span. They point to the fact that how we are at older ages is also the result of all that has happened before. Therefore, companies should not limit their interventions to older workers but focus on creating 'development friendly' work contexts that support productive performance and development across the adult life span that is they need to start with newly recruited employees.

Gajewski and Falkenstein ("Neurocognition of Aging in Working Environments") argue that aging is accompanied by changes in sensory, motor and cognitive functions. They emphasize that a high status of so called fluid cognitive functions-e.g. the capacity to shift attention and tasks, to 
suppress unwanted information and actions and to act adequately in novel situations- is crucial for the employability of older workers. The decline of these functions is accelerated by adverse environmental and occupational factors, while it can be attenuated by cognitively challenging work or other activities. This underlines the responsibility of employers to create and maintain a cognitively efficient and innovative workforce by both person-centered and situationcentered interventions.

Frosch, Göbel and Zwick ("Separating Wheat and Chaff: Age-related Staffing Patterns and Innovation at the Establishment Level") investigate to what extent the innovative capacity of German firms is influenced by their staffing patterns. They find that most of the 585 German establishments covered in their analysis rejuvenate their workforce through inflows of younger workers, and that half of them also do so through the outflow of older workers. Their results indicate that firms' innovative performance is not significantly related to staffing patterns: Innovation is not demonstrably fostered by either the inflow of young professionals or by the retention of older experienced workers.

Trautmann, Volcker-Rehage and Godde ("Fit between workers competencies and job demands as predictor for job performance over the work career") show that both excessive and under-challenging work demands, indicating a misfit between individual competencies and task relevant demands, result in a decrease of job performance. The same is true for a misfit between the supervisor- and employee-rated abilities to learn new tasks. Employees in less demanding and supporting work contexts might lack the incentives to train themselves even during their leisure time, leading to reduced readiness and capacity for flexibility. The authors conclude that an early identification and prevention of a misfit between work place specific demands and individual competencies is likely to maintain or increase task performance in older age.

Dietz and Walwei ("Germany-No Country for Old Workers?") provide a general assessment of the employment situation for the elderly in Germany. In recent years, the gloomy picture has brightened considerably due to a number of different factors: the better overall development of the labor market, an increased labor force participation of women, reduced early exit options for older workers and far-reaching institutional changes in public pension and unemployment benefit schemes. Nevertheless, certain groups of older workers still have a hard time on the German labor market, most notably the low-skilled. Moreover, older persons who are already unemployed have great difficulties to (re-)enter the labor market.

Börsch-Supan ("Health and Disability Insurance") addresses the question of why enrollment rates in disability insurance vary strikingly across European countries and the US. He argues that it is not health but country-specific disability insurance rules, i.e. the generosity of disability pension schemes that explain the lion share of the observed cross-country variation.

Michael Falkenstein

Joachim Möller

Ursula M. Staudinger 